\title{
HIGH-MOBILITY GROUP PROTEIN HMGA2-DERIVED FRAGMENTS STIMULATE THE PROLIFERATION OF CHONDROCYTES AND ADIPOSE TISSUE-DERIVED STEM CELLS
}

\author{
A. Richter ${ }^{1}$, M. Lübbing ${ }^{1,2}$, H.-G. Frank ${ }^{3}$, I. Nolte ${ }^{2}$, J. Bullerdiek ${ }^{1,2 *}$ and I. von Ahsen ${ }^{1,2}$ \\ ${ }^{1}$ Centre for Human Genetics, University of Bremen, Germany \\ ${ }^{2}$ Clinic for Small Animals and Research Cluster of Excellence "Rebirth", University of Veterinary Medicine, \\ Hanover, Germany \\ ${ }^{3}$ AplaGen GmbH, Baesweiler, Germany
}

\begin{abstract}
In previous research, it was shown that recombinant HMGA2 protein enhances the proliferation of porcine chondrocytes grown in vitro, opening up promising applications of this embryonic architectural transcription factor for tissue engineering, such as in cartilage repair. In this paper, we describe the development and analyses of two synthetic fragments comprising the functional AT-hook motifs of the HMGA2 protein, as well as the nuclear transport domain. They can be synthesised up to large scales, while eliminating some of the problems of recombinant protein production, including unwanted modification or contamination by the expression hosts, or of gene therapy approaches such as uncontrolled viral integration and transgene expression even after therapy. Application of one of these peptides onto porcine hyaline cartilage chondrocytes, grown in in vitro monolayer cell culture, showed a growth-promoting effect similar to that of the wild type HMGA2 protein. Furthermore, it also promoted cell growth of adult adipose tissue derived stem cells. Due to its proliferation inducing function and vast availability, this peptide is thus suitable for further application and investigation in various fields such as tissue engineering and stem cell research.
\end{abstract}

Keywords: High-mobility-group protein A2, cartilage, chondrocytes, adipose tissue derived stem cells, tissue regeneration.
*Address for correspondence:

J. Bullerdiek

Centre for Human Genetics,

University of Bremen,

Leobener Strasse ZHG, 28359 Bremen, Germany

Telephone Number: +49-421-218-61501

FAX Number: +49-421-218-61505

E-mail: bullerd@uni-bremen.de

\section{Introduction}

Recombinant High-Mobility-Group A2 (HMGA2) proteins have been shown to significantly increase the proliferative activity of chondrocytes in a dose-dependent manner in an in vitro system of porcine origin (Richter et al., 2009). Since articular cartilage defects are a major problem in patients from all ages, this opens up future possibilities to improve cell yield for in vitro propagation of these cells.

However, in terms of a perspective therapeutic application of this protein and its authorisation, the recombinant HMGA2 protein production process has some disadvantages, including potential unwanted modifications of the protein by the expression hosts, microbial contamination including foreign DNA and proteins, as well as further contamination e.g. from the growth medium that all need to be taken care of. To avoid these issues, we developed two peptide fragments HMGA2-A (60mer) and HMGA2-B (80mer) that are synthesised by microwave assisted solid phase peptide synthesis thus eliminating any steps involving prokaryotic or eukaryotic protein expression systems and providing the ability of large scale synthesis of these biologically active substances for future fields of application in e.g. tissue engineering. This peptide approach also enables the direct application of the active agent only during the phase of treatment, as opposed to e.g. virus based delivery systems, where uncontrolled viral integration, genomic instability, and transgene expression even after therapy may occur, and also makes possible the direct delivery of the molecules into the cells due to the small molecule nature of the developed peptides. The two peptides or fragments thereof are expected to show comparable effects to the native protein by comprising the eponymous biologically active AT-hooks of HMGA2, which bind to the minor groove of AT-rich DNA and thereby influence DNA conformation and binding of various transcription factors, finally influencing the activity of a large number of genes (Reeves and Beckerbauer, 2001).

As HMGA2 has virtually no secondary structure (Reeves and Beckerbauer, 2003), it allows for the use of synthesised peptides of parts thereof, i.e. in this case the DNA binding AT-hooks, without further modification. In previous research, it had been shown that synthetic peptides comprising only the 3 AT-hooks still possess the DNA-binding capability of the native protein (Geierstanger et al., 1994); however, the focus was not set on any function besides DNA-binding. Later it was shown that truncated HMGA2 lacking the carboxy-terminus led 


\section{Peptide HMGA2A (60mer)}

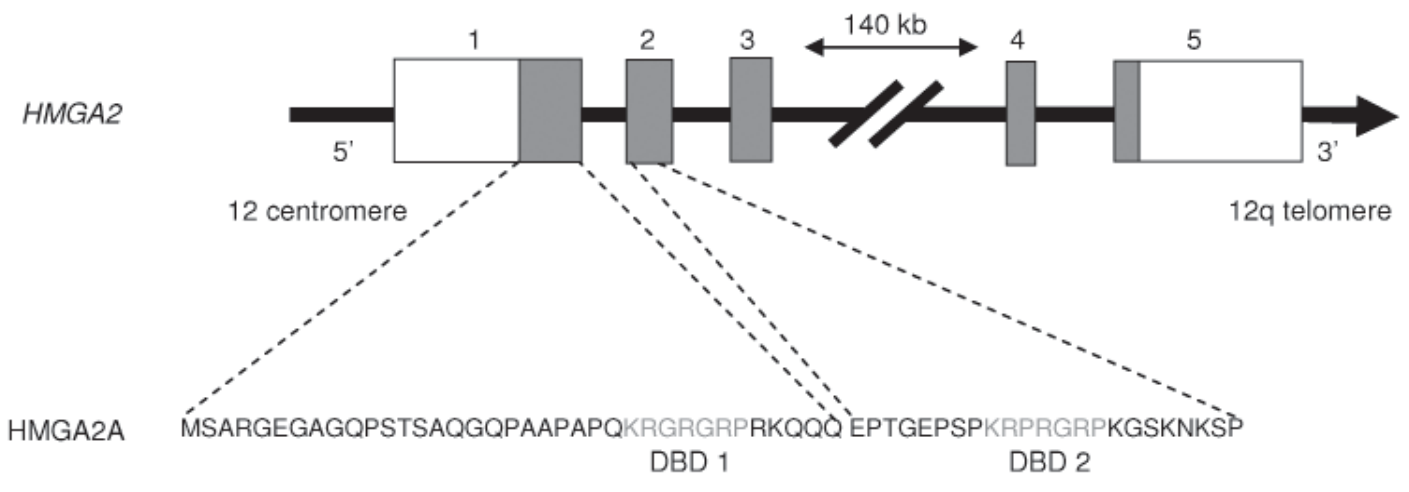

Peptide HMGA2B (80mer)

HMGA2

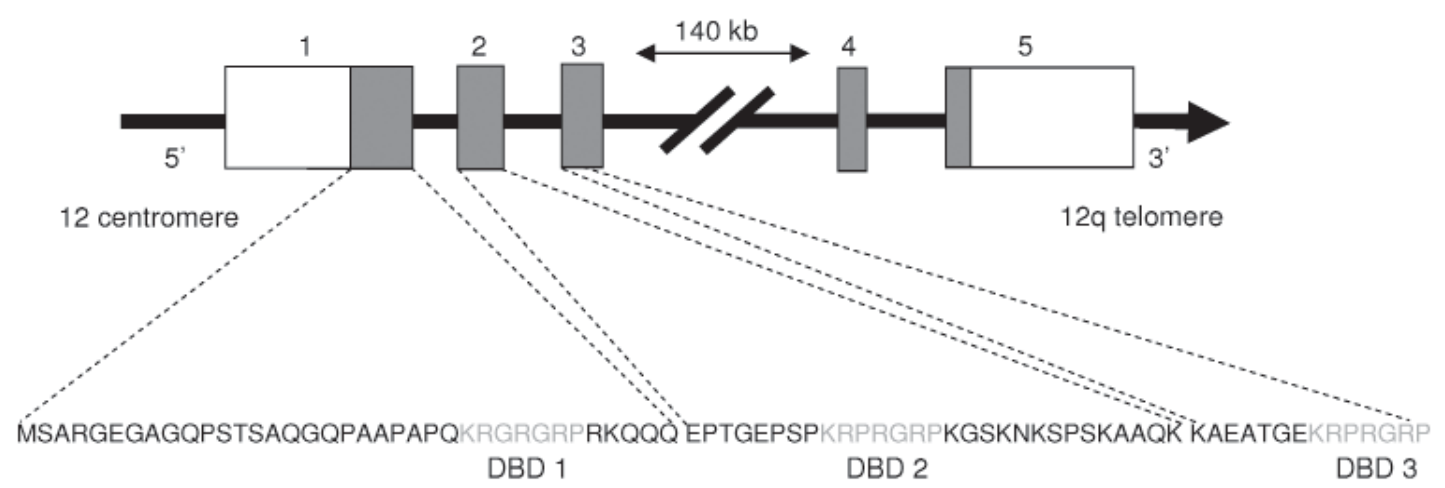

Fig. 1. Amino acid sequence and structure of the two HMGA2 peptides. DBD = DNA binding domain.

to increased growth of NIH3T3 cells as compared to wild type HMGA2 (Fedele et al., 1998) and remains functional in recombinant mice (Battista et al., 1999).

While the function of the AT-hooks is thus well-known and described (Reeves and Nissen, 1990; Geierstanger et al., 1994; Chau et al., 1995; Goodwin, 1998; Reeves, 2000; Cattaruzzi et al., 2007; Cleynen and Van de Ven, 2008), the role of the acidic C-terminus is still not well understood, but it is assumed that it is responsible in parts, amongst others, for the protein binding capacity of HMGA2 (Noro et al., 2003), and sequence specificity of DNA-binding (Yie et al., 1997).

The aim of this study therefore was the evaluation of the two newly synthesised fragments of HMGA2 in respect to cell growth in the same in vitro cell culture system as described before (Richter et al., 2009), as well as to the cell penetration / DNA-binding capacity which was determined by fluorescence microscopy of a labelled variant of the HMGA2-B peptide (HMGA2-CC). In addition to porcine chondrocytes, the peptides were also applied to canine adult adipose tissue derived stem cells (ADSCs), as these can be differentiated into chondrogenic cells in the presence of lineage-specific induction factors including insulin and TGF- $\beta$, leading to the formation of hyaline cartilage (Zuk et al., 2001; Huang et al., 2004).

\section{Materials and Methods}

\section{HMGA2 fragment synthesis}

Two fully synthetic HMGA2 fragments (60 AA and 80 AA, Fig. 1) were synthesised at a scale of $0.25 \mathrm{mmol}$ by microwave assisted solid phase peptide synthesis in an automated Liberty unit (CEM, Kamp-Lintfort, Germany). The growing peptide chain was assembled on PAL ChemMatrix resin (Matrix Innovation, Montreal, Canada). Deprotection was achieved by adding $10 \mathrm{~mL}$ Piperidine (5\% in dimethylformamide / $0.1 \mathrm{M} \mathrm{HOBt}$ (Biosolve BV, Valkenswaard, Netherlands)) and irridation with $65 \mathrm{~W}$ for $3 \mathrm{~min}$. Coupling of the next amino acid was achieved using a fivefold excess of reagents (amino acid, Pyclock (Livchem, Frankfurt/Main, Germany), Cl-HOBt (Biosolve, Valkenswaard, Netherlands), Diisopropylethylamine (Iris Biotech, Marktredwitz, Germany)) in $10 \mathrm{~mL}$ dimethylformamide and irradiation with $40 \mathrm{~W}$ for $5 \mathrm{~min}$. All couplings were done by a double coupling procedure including capping with $\mathrm{Z}-2-\mathrm{Br}-\mathrm{OSu}$ (Iris Biotech, Marktredwitz, Germany). After washing with dichloromethane, the peptide was cleaved by adding $40 \mathrm{~mL}$ cleavage cocktail (94\% trifluoroacetic acid, 1.0\% triisopropylsilane (Sigma, Deisenhofen, Germany), $2.5 \% \mathrm{H}_{2} \mathrm{O}, 2.5 \%$ 3,6-Dioxa-1,8-octandithiol (Sigma, 
a) HPLC

\begin{tabular}{|c|c|c|c|c|c|}
\hline \multicolumn{6}{|c|}{ Detector A (216nm) } \\
\hline 1 & 12.883 & 452952 & 5.903 & 51442 & 8.009 \\
\hline 2 & 13,075 & 6613553 & 86,183 & 536085 & 83,460 \\
\hline 3 & 13,375 & 570683 & 7.437 & 49463 & 7,701 \\
\hline 4 & 36.333 & 36631 & 0.477 & 5337 & 0.831 \\
\hline Totals & & 7673819 & 100,000 & 642327 & 100,000 \\
\hline
\end{tabular}

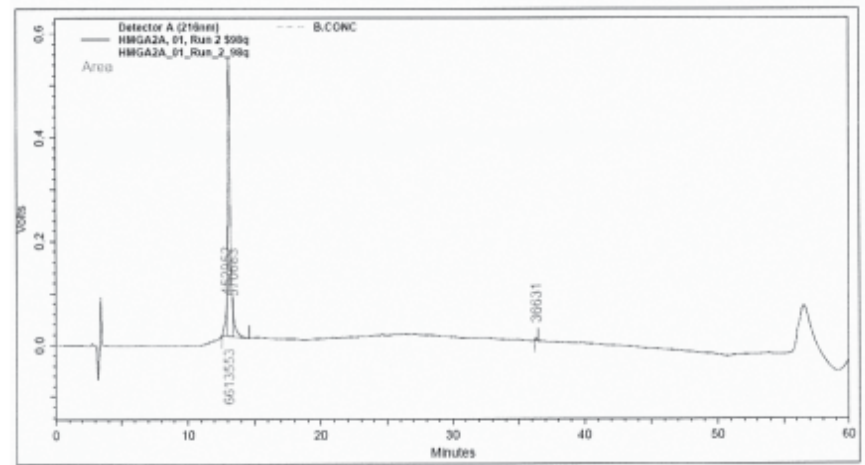

b) ESI-MS

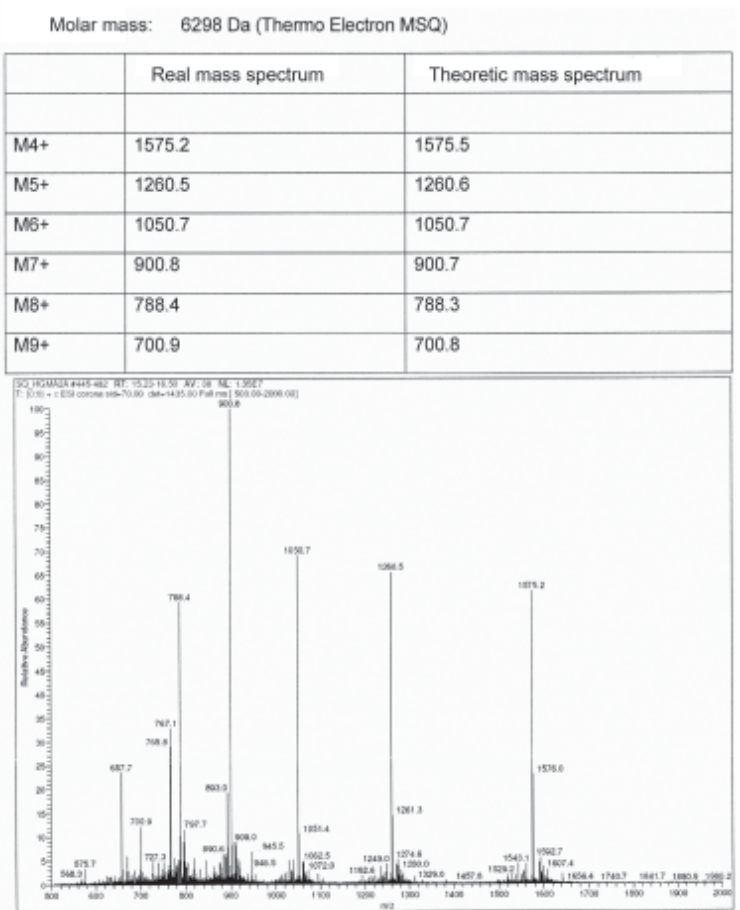

Fig. 2. HPLC and ESI-MS analysis of the HMGA2-A synthesis product.

Deisenhofen, Germany)) and reaction at room temperature for $3 \mathrm{~h}$. The peptide was then precipitated in $160 \mathrm{~mL}$ cold ether, solved in acetonitrile/water and purified by Liquid chromatography-mass spectrometry (LC-MS) using a Nebula (Gilson) purification system (Column: C18 reprosil $10010 \mu \mathrm{m} 250$ x 20mm; flow rate: $20 \mathrm{~mL} / \mathrm{min}$; eluent A: water and $0.1 \%$ TFA; eluent B: acetonitrile \& $0.085 \%$ TFA). Analysis of the purified peptides was performed by HPLC (Column: Phenomenex Gemini $5 \mu \mathrm{m} 110$ A $4.6 \mathrm{~mm}$ x $250 \mathrm{~mm}$, eluent A: water \& $0.1 \% \mathrm{TFA}$; eluent B: acetonitrile \& $0.085 \%$ TFA; flow rate: $1 \mathrm{~mL} / \mathrm{min}$ ) and electrospray-ionisation mass spectrometry (ESI-MS) (Fig. 2: HMGA2-A and Fig. 3: HMGA2-B).

\section{Synthesis of the carboxyfluorescein labelled HMGA2-B variant}

The carboxyfluorescein labelled variant of the HMGA2-B peptide was synthesised as described above, with additional coupling of 5/6-carboxyfluorescein to the N-terminus at the final step of the solid phase synthesis. In this procedure, the label was coupled to the solid phase, i.e. all reactive groups excluding the $\mathrm{N}$-terminus were still protected leading to selective N-terminal labelling of the peptide. For this cause, no further validation of the $\mathrm{N}$-terminal coupling of the label was performed as it can be assumed from the procedure that the label can only bind to the $\mathrm{N}$-terminus of the peptide. Coupling was performed by the use of N,N'Diisopropylcarbodiimid (Sigma) / HOBt and coupling for $12 \mathrm{~h}$ at room temperature. The labelled fragment was then purified as described above.

\section{Expression and purification of recombinant HMGA2 protein}

Recombinant HMGA2 produced using the Novagen pET System (Merck Chemicals, Darmstadt, Germany) following a protocol adapted from Schwanbeck (1995) served as a positive control. The complete coding sequences of $H M G A 2$ was inserted into the pET3a vector. Subsequently, transformation of the non-expression host E. coli $\mathrm{DH} 5 \alpha$ with these plasmids was performed for verification by sequencing and long term storage. Protein expression was performed with freshly transformed $E$. coli BL21(DE3) Rosetta pLysS (Merck Chemicals). A preparatory culture was grown to an OD of 0.6 in $10 \mathrm{~mL}$ LB broth supplied with $100 \mu \mathrm{g} / \mathrm{mL}$ ampicillin, $34 \mu \mathrm{g} / \mathrm{mL}$ chloramphenicol and $1 \%(\mathrm{w} / \mathrm{v})$ glucose. After inoculation, 1L of expression culture (LB broth supplied with $100 \mu \mathrm{g}$ / $\mathrm{mL}$ ampicillin, $34 \mu \mathrm{g} / \mathrm{mL}$ chloramphenicol and $0.5 \%(\mathrm{w} / \mathrm{v})$ glucose) was grown to an OD of 0.6 , followed by induction of protein expression with $1 \mathrm{mmol} / 1$ IPTG. Expression was performed for $120 \mathrm{~min}$ at $37^{\circ} \mathrm{C}$, the culture was thereafter stored on ice and then pelleted by centrifugation.

HMGA2 and other acid soluble proteins were recovered from the bacteria by performing a combined three cycle freeze $\left(-20^{\circ} \mathrm{C}\right)$ and thaw and acidic precipitation procedure with $3 \mathrm{x}(\mathrm{w} / \mathrm{v}) 5 \%$ perchloric acid, resulting in lysis of bacterial cells and precipitation of bacterial debris and non-acid soluble proteins. Following centrifugation, the HMGA2-containing supernatant was removed and acidified with $37 \% \mathrm{HCl}$ to a final concentration of $0.35 \mathrm{M}$ $\mathrm{HCl}$. Precipitation of HMGA2 proteins was performed by 
a) HPLC

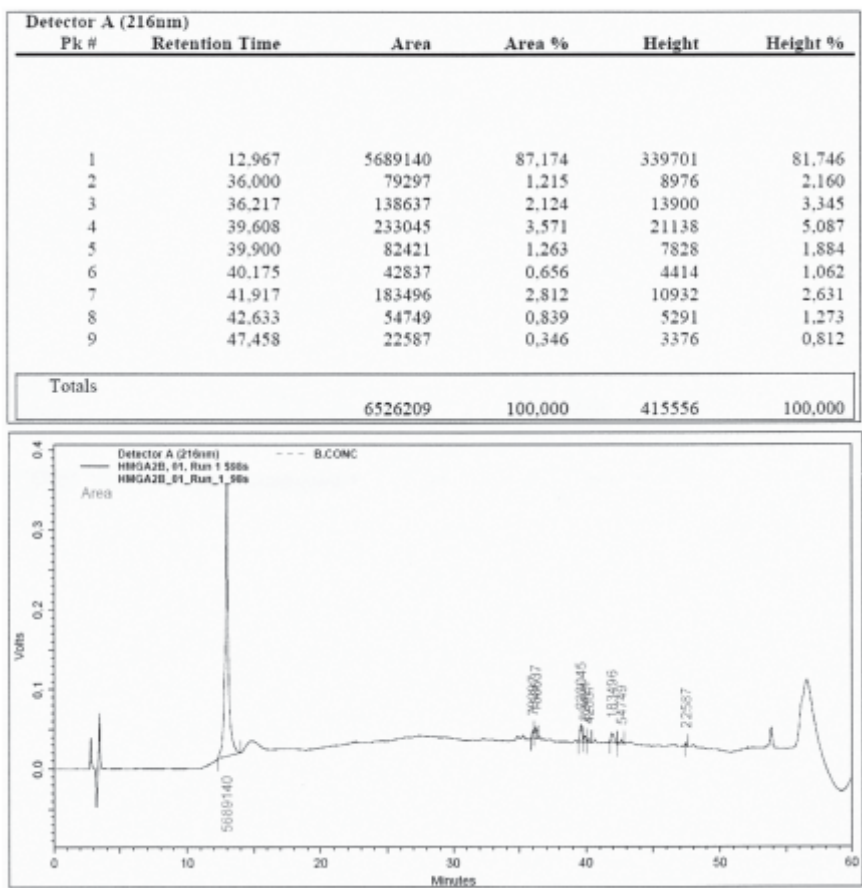

b) ESI-MS

Molar mass: $8447 \mathrm{Da}$ (Thermo Electron MSQ)

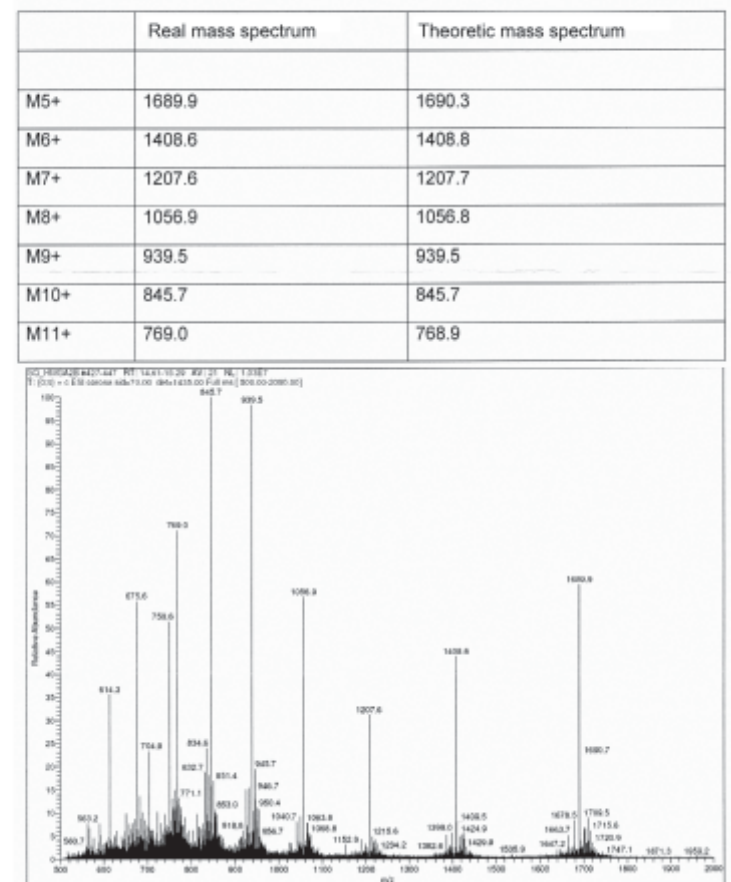

Fig. 3. HPLC and ESI-MS analysis of the HMGA2-B synthesis product.

adding $6 \mathrm{x}$ vol. of $-20{ }^{\circ} \mathrm{C}$ acetone. Protein was pelleted by centrifugation in $80 \mathrm{~mL}$ glass tubes, the acetone supernatant carefully removed, the pellet frozen to $-80{ }^{\circ} \mathrm{C}$ and dried under vacuum. Pelleted protein was resolved using $50 \mathrm{mM}$ ammonium hydrogen carbonate at $4{ }^{\circ} \mathrm{C}$. This crude acid soluble protein mix containing mostly HMGA2 was stored until further processing at $-80{ }^{\circ} \mathrm{C}$.

Final purification of HMGA2 protein was performed using a 2-step HPLC procedure. In the first step, acid soluble bacterial proteins as well as bacterial DNA which were carried over from acetone precipitation were removed using a cation exchange column (TSKgel SP5 PW 20 $\mu \mathrm{m}$, Tosoh Bioscience GmbH, Stuttgart, Germany) and a gradient of $25 \mathrm{mM} \mathrm{H}_{3} \mathrm{BO}_{3} \mathrm{pH} 9.4$ and $25 \mathrm{mM} \mathrm{H}_{3} \mathrm{BO}_{3} / 1 \mathrm{M}$ $\mathrm{NaCl} \mathrm{pH}$ 9.4. Due to the lack of aromatic amino acid in HMGA2 protein, identification of the HMGA2 fraction was achieved using a $215 \mathrm{~nm}$ absorption peak proximal to the absorption maximum of the peptide bond at 205 $\mathrm{nm}$. Following this first purification step, a reverse phase HPLC purification (Grom-Sil 300 ODS-5 ST, Grom, Rottenburg-Hailfingen, Germany) with a gradient of $0.1 \%$ TFA and $0.1 \%$ TFA $/ 70 \% \mathrm{ACN}$ of the fraction obtained was performed enabling the removal of degraded or fragmentary HMGA2, leading to a very pure fraction of intact protein. Quality control was performed by PAGE (data not shown). For removal of eluent, gravimetric quantitation, and long term storage, fraction volume was first reduced using Amicon Ultra 10000 MWCO Centrifugation devices (Millipore, Schwalbach, Germany) and then lyophilised using a freeze dryer. Gravimetric quantitation of the resulting HMGA2 pellets was performed on an analytical balance (Sartorius, Goettingen, Germany), and the pellets frozen at $-80^{\circ} \mathrm{C}$ for long term storage. A stock solution of $10 \mu \mathrm{g} / \mathrm{mL}$ HMGA2 was then prepared from the lyophilisate for use in the cell proliferation assays.

\section{Cell culture}

Chondrocytes were obtained from the knee joint of an approximately four month old pig for slaughter, which was culled for meat production at a butchery that is subject to the German animal protection law and licensed for meat production by the Federal Office of Consumer Protection and Food Safety, which implies ethical treatment of the animals slaughtered. Cartilage was carefully removed excluding the calcified inner cartilage layer using a punch and a scalpel. The cartilage pieces were further chopped and digested for $6 \mathrm{~h}$ under continuous shaking at $37^{\circ} \mathrm{C}$ / $5 \% \mathrm{CO}_{2}$ in $50 \% \mathrm{v} / \mathrm{v} 0.26 \%$ collagenase NB8 (Serva Electrophoresis $\mathrm{GmbH}$, Heidelberg, Germany) and tissue culture medium (medium 199 containing Earle's salts and L-glutamine (Invitrogen, Karlsruhe, Germany), 200 IU Penicillin \& $200 \mathrm{mg} / \mathrm{mL}$ Streptomycin (Biochrom, Berlin, Germany), and 10\% foetal bovine serum (Invitrogen, Karlsruhe, Germany)) until the chondrocytes were released from the extracellular cartilage matrix. Following digestion, the released cells were filtered from the undigested cartilage residue, washed and transferred to a $25 \mathrm{~cm}^{2}$ tissue culture flask (Nunc, Wiesbaden, Germany). They were incubated at $37{ }^{\circ} \mathrm{C} / 5 \% \mathrm{CO}_{2} / 5 \mathrm{~mL}$ tissue culture medium as described previously until $3 / 4$ confluency of the TC-flask was reached. This was followed by one further passage.

Canine subcutaneous adipose tissue of the abdominal region was taken during surgery from dogs admitted to the 
Small Animal Clinic, University of Veterinary Medicine (Hanover, Germany). The adipose tissue was transferred into sterile Hank's solution and minced into small pieces followed by treatment with $0.26 \%$ collagenase NB8. After 1-2 h, the dissociated cells were transferred into sterile flasks containing $5 \mathrm{~mL}$ tissue culture medium 199 / 20\% FCS. The flasks were incubated at $37{ }^{\circ} \mathrm{C} / 5 \% \mathrm{CO}_{2}$ and medium was replaced every 2-3 d. Stem cells were selected for by their adherence to the plastic surface of the cell culture flask (Dominici et al., 2006) and passaged when they reached approximately $80 \%$ confluence.

\section{Cell penetration assay and fluorescence microscopy}

Porcine chondrocytes were seeded onto glass plates $\left(\mathrm{A}=1.76 \mathrm{~cm}^{2}\right)$ positioned in a sterile plastic 12 -well microtiter plate and incubated for $24 \mathrm{~h}$ at $37{ }^{\circ} \mathrm{C} / 5 \% \mathrm{CO}_{2}$ (100,000 cells / well in $1 \mathrm{~mL}$ of medium 199/10\% FCS). Following incubation, the medium was replaced with 0.5 mL of medium 199/10\% FCS (non peptide control), 0.5 mL of medium 199/10\% FCS + $10 \mu \mathrm{M}$ HMGA2-CC, and $0.5 \mathrm{~mL}$ of medium 199/10\% FCS $+50 \mu \mathrm{M}$ HMGA2$\mathrm{CC}$, respectively, and the cells incubated a further $4 \mathrm{~h}$ at $37{ }^{\circ} \mathrm{C} / 5 \% \mathrm{CO}_{2}$. Thereupon, the medium was replaced with $1 \mathrm{~mL}$ of medium $199 / 10 \% \mathrm{FCS}+25 \mu \mathrm{g} / \mathrm{mL}$ DAPI $+1 \mu \mathrm{g} / \mathrm{mL}$ propidium iodide (PI) followed by a further incubation time of $5 \mathrm{~min}$ at room temperature. Cells were washed three times with $1 \mathrm{~mL}$ medium $199 / 10 \%$ FCS to remove residual stains. The glass plates were removed from the 12-well plate and embedded onto glass slides, using rubber cement, for analysis. Uptake of fluorescently labelled HMGA2-CC peptides was determined by fluorescence microscopy utilising a Carl Zeiss Axioskope and documented electronically by Axiovision 4.5 software using green (GFP, FITC), blue (DAPI), and red (PI) filters (Carl-Zeiss-AG, Oberkochen, Germany).

Canine ADSCs were subjected to a slightly modified procedure, where 50,000 cells/well in M199 + 10\% FCS were seeded into a 24 -well plate such that the next day a density of about $50 \%$ was achieved. The medium was removed and for each condition to be tested a solution of M199/10\% FCS with HMGA2-CC (100 $\mu \mathrm{M}, 50 \mu \mathrm{M}$, $10 \mu \mathrm{M}$ and $0 \mu \mathrm{M}$, respectively), bisbenzimide $(0.1 \mu \mathrm{g} /$ $\mathrm{mL})$ and PI $(1 \mu \mathrm{g} / \mathrm{mL})$ was added to the cells. Cells were incubated at $37{ }^{\circ} \mathrm{C}$ for $4 \mathrm{~h}$, washed in M199 and put in Hank's buffered saline solution (HBSS) for immediate analysis of fluorescence. Living cells were checked and photographed by fluorescence microscopy using green (GFP, FITC), blue (bisbenzimide), and red (PI) filters and the $20 \mathrm{x}$ objective. Overlay pictures were produced using Leica application suite software.

\section{In vitro cell proliferation assay}

The proliferative effects of HMGA2-A and HMGA2-B were examined using the BrdU cell proliferation ELISA kit (colorimetric) (Roche Diagnostics, Mannheim, Germany) according to the manufacturer's instructions. Conditions to be tested for porcine chondrocytes were $10 \mu \mathrm{M}$ and $50 \mu \mathrm{M}$ of HMGA2-A as well as $10 \mu \mathrm{M}$ and $50 \mu \mathrm{M}$ of HMGA2-B, with $10 \mu \mathrm{M}$ recombinant HMGA2 and $0 \mu \mathrm{M}$ HMGA2 serving as controls. Chondrocytes were harvested using TrypLE Express (Gibco, Karlsruhe, Germany), washed and resuspended in fresh tissue culture medium as described previously and adjusted to 150,000 cells/mL. For each parameter or control, 8 consecutive wells of a 96-well cell culture microtiter plate (Nunc, Wiesbaden, Germany) were seeded with 7,500 cells/well in $50 \mu \mathrm{L}$ of M199/10\%FCS. Cells were left to settle for three hours at $37{ }^{\circ} \mathrm{C} / 5 \%$ $\mathrm{CO}_{2}$. To each test condition, dilutions of HMGA2-A and HMGA2-B as well as recombinant HMGA2 solution and the non-peptide/protein control were added to the final concentrations of $0 \mu \mathrm{M}, 10 \mu \mathrm{M}$ or $50 \mu \mathrm{M}$, respectively, in a total volume of $100 \mu \mathrm{L}$. Cells were left at $37^{\circ} \mathrm{C} /$ $5 \% \mathrm{CO}_{2}$ for $17 \mathrm{~h}$ followed by the addition of BrdU. After an incubation period of $7 \mathrm{~h}$ at $37{ }^{\circ} \mathrm{C} / 5 \% \mathrm{CO}_{2}$, BrdU incorporation was detected with the BioTek Synergy HT microtiter plate reader (BioTek Instruments $\mathrm{GmbH}$, Bad Friedrichshall, Germany) and interpreted by spreadsheet analysis. Data was normalised using the non-HMGA2 control as reference value.

The in vitro cell proliferation assay of ADSCs was performed with the same BrDU ELISA procedure, with some cell type specific modifications. Conditions to be tested were $5 \mu \mathrm{M}$ and $50 \mu \mathrm{M}$ HMGA2-A, as well as 5 and $50 \mu \mathrm{M}$ HMGA2-B, compared to a non peptide $(0$ $\mu \mathrm{M})$ control. Cells were grown in M199/10\% FCS and seeded into the wells of a 96 well flat bottom plate at a density of $10^{4}$ cells in $100 \mu \mathrm{L}$ M199 per well. Following attachment of cells to the bottom of the wells, the culture medium was replaced with M199/1\%FCS which was left on the cells for $24 \mathrm{~h}$. Finally, this was replaced with M199/1\%FCS containing the peptides at the concentrations mentioned above as well as the non peptide control. After $6 \mathrm{~h}$ of incubation, BrdU was added to each well to a final concentration of $10 \mu \mathrm{M}$. Another incubation of $18 \mathrm{~h}$ followed after which the measurement of cell proliferation was performed as described in the chondrocyte section.

\section{Statistics}

Statistical analysis was performed with GraphPad Instat and GraphPad Prism 5 software (GraphPad Software, La Jolla, CA, USA) using the one-way ANOVA (ANalysis Of VAriance), with pairs of group means being compared using the Tukey-Kramer Multiple Comparisons Test. The significance level was set at $P<0.01$. Identity of standard deviations was checked using Bartlett's test, and Gaussian distribution of sample data was tested by the KolmogorovSmirnov method.

\section{Results}

\section{Cell penetration assay}

By fluorescence microscopy, a green stain caused by the accumulation of fluorescently labelled HMGA2-CC peptides was detected in the nuclei of $51 \%$ of chondrocytes for both cells incubated with $10 \mu \mathrm{m}$ peptide (not shown) and $50 \mu \mathrm{m}$ peptide (Fig. 4 a-e), respectively, and in $24 \%$ of ADSCs at $100 \mu \mathrm{m}$ peptide (Fig. $4 \mathrm{f}-\mathrm{k}, 10 \mu \mathrm{M}$ and 50 $\mu \mathrm{M}$ peptide not shown). Green fluorescence could also be detected in the cytoplasm of most chondrocytes and ADSCs, even when no intensely stained green nuclei were present. Nevertheless, all cells displayed the typical blue 


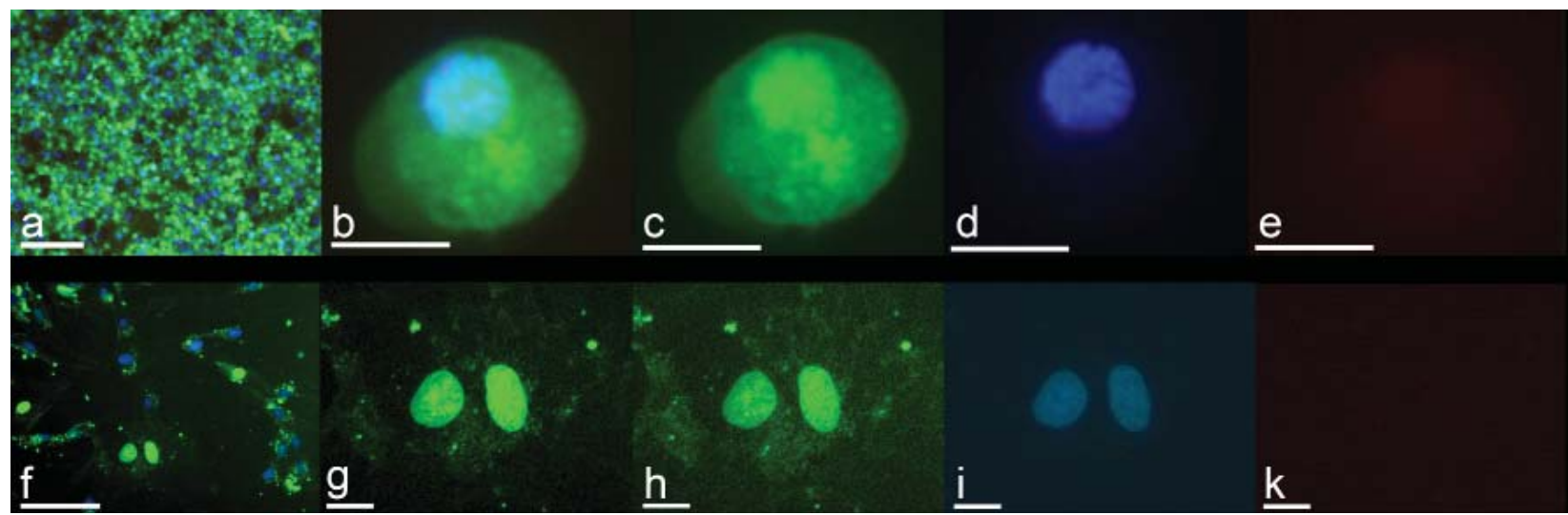

Fig. 4. Transfection of porcine chondrocytes (a-e) and canine ADSCs (f-k) in in vitro monolayer cell culture with the fluorescently labelled HMGA2-CC peptide. (a) Overview of porcine chondrocytes showing the green fluorescence of HMGA2-CC in 51\% of the cells as well as the blue DAPI stain in the nuclei of all cells. (b) Single chondrocyte with combined green HMGA2-CC and blue DAPI stains. (c) Single chondrocyte with green HMGA2-CC stain showing the presence of HMGA2-CC in the cytoplasm as well as the nucleus. (d) Single chondrocyte with blue DAPI stain in the nucleus. (e) Single chondrocyte showing no signs of cell damage or death as no PI stain could be detected. (f) Overview of canine ADSCs showing the green fluorescence of HMGA2-CC in 24\% of the cells as well as the blue DAPI stain in the nuclei of all cells (g) two ADSCs with combined green HMGA2-CC and blue DAPI stains (h) green channel only (HMGA2-CC) (i) blue channel only (DAPI), (k) red channel only (PI). Scale bars: $100 \mu \mathrm{m}$ in a and $\mathbf{f} ; 10 \mu \mathrm{m}$ in $\mathbf{b}-\mathbf{e} ; 20 \mu \mathrm{m}$ in $\mathbf{g - k}$.
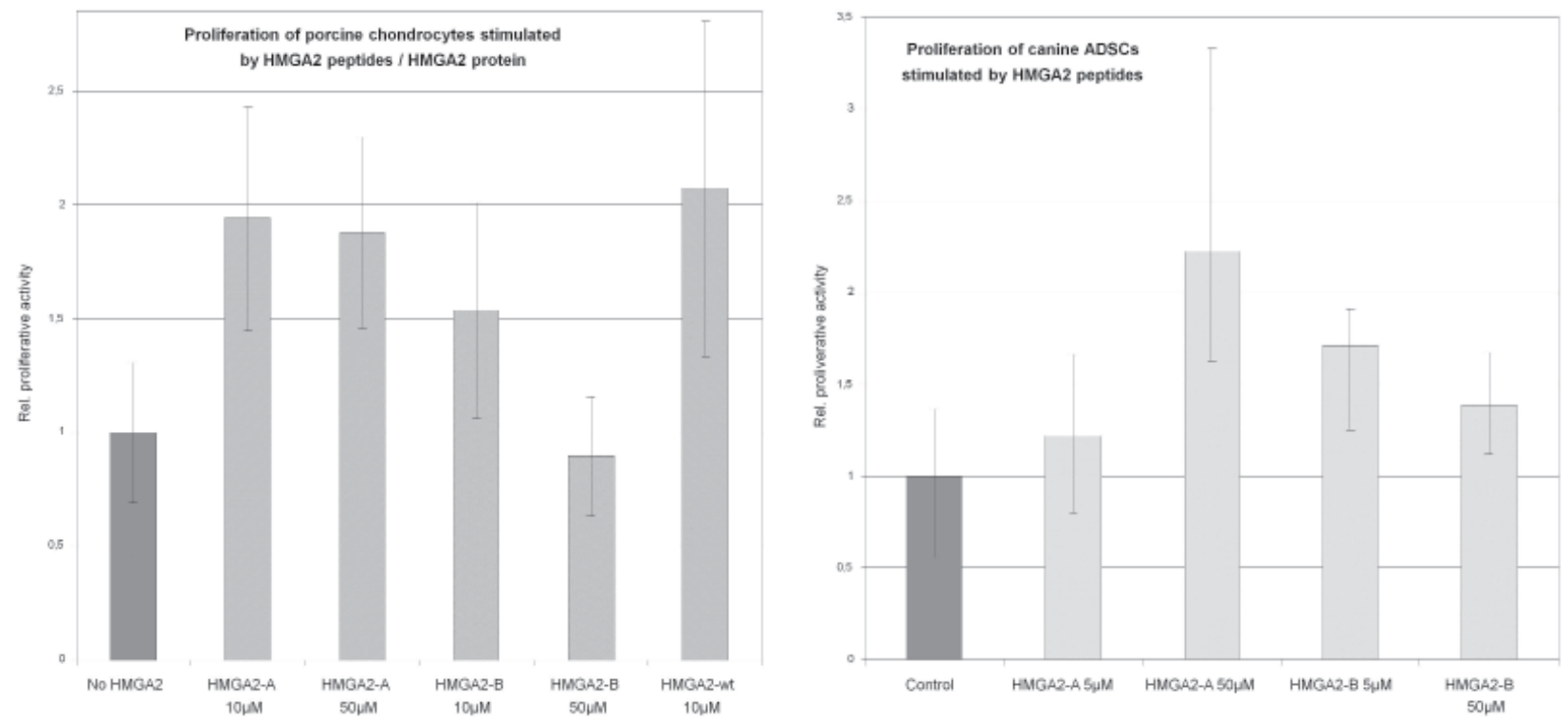

Fig. 5. Cell proliferation of porcine hyaline cartilage cells (a) and canine ADSCs (b) induced by the addition of HMGA2 peptides. Values obtained by the microtiter plate reader were normalised to the absorbance of the non-HMG control which was set as 1. Error bars: standard deviation.

DAPI or bisbenzimidine stain in the nucleus. No dead cells were detected as revealed by lack of simultaneous red fluorescence (PI) of the nuclei.

\section{Colorimetric Cell Proliferation ELISA}

Proliferation of porcine chondrocytes and canine ADSCs in response to two different peptides of human HMGA2, as well as wild type HMGA2 protein in case of the chondrocytes, was examined in in vitro ELISA-based assays. For comparability, the absorbance values obtained from the microtiter plate reader were normalised to the values of the non-HMGA2 control, which was set to a value of 1 (Fig. 5).
To see if the data were suitable for ANOVA, they were subjected to the Bartlett's test which did not show significant differences between the standard deviations of the different groups in both the chondrocyte and ADSC assays. Gaussian distribution of data was tested by the Kolmogorov-Smirnov method with all populations passing the normality test. Deducing from these test results, data were usable for ANOVA. The one way ANOVA resulted in a $P$ value $<0.0001$ for both chondrocytes and ADSCs, showing that variation among column means is significantly greater than expected by chance. For determination of group differences, pairs of group means were compared 
Table 1. Tukey-Kramer Multiple Comparisons on the effect of different HMGA2 peptides and wild type HMGA2 protein on the proliferation of porcine chondrocytes (a), as well as HMGA2 peptides on the proliferation of canine ADSCs (b). Grey cells indicate significant differences with a $P$ value $<0.01$.

\begin{tabular}{|c|c|c|c|c|c|c|}
\hline (a) & Control & $\begin{array}{c}\text { HMGA2-A } \\
\mathbf{1 0} \boldsymbol{\mu M}\end{array}$ & $\begin{array}{c}\text { HMGA2-A } \\
\mathbf{5 0} \boldsymbol{\mu M}\end{array}$ & $\begin{array}{c}\text { HMGA2-B } \\
\mathbf{1 0} \boldsymbol{\mu M}\end{array}$ & $\begin{array}{c}\text { HMGA2-B } \\
\mathbf{5 0} \boldsymbol{\mu M}\end{array}$ & $\begin{array}{c}\text { HMGA2- } \\
\text { wt 10 } \boldsymbol{\mu M}\end{array}$ \\
\hline Control & & & & & \\
\hline $\begin{array}{c}\text { HMGA2-A } \\
\mathbf{1 0} \boldsymbol{\mu M}\end{array}$ & $<0.01$ & & & & & \\
\hline $\begin{array}{c}\text { HMGA2-A } \\
\mathbf{5 0} \boldsymbol{\mu M}\end{array}$ & $<0.01$ & $>0.05$ & & & & \\
\hline $\begin{array}{c}\text { HMGA2-B } \\
\mathbf{1 0} \boldsymbol{\mu M}\end{array}$ & $>0.05$ & $>0.05$ & $>0.05$ & & & \\
\hline $\begin{array}{c}\text { HMGA2-B } \\
\mathbf{5 0} \boldsymbol{\mu M}\end{array}$ & $>0.05$ & $<0.01$ & $<0.01$ & $>0.05$ & & \\
\hline $\begin{array}{c}\text { HMGA2-wt } \\
\mathbf{1 0} \boldsymbol{\mu M}\end{array}$ & $<0.001$ & $>0.05$ & $>0.05$ & $>0.05$ & $<0.01$ \\
\hline
\end{tabular}

\begin{tabular}{|c|c|c|c|c|c|}
\hline (b) & Control & $\begin{array}{c}\text { HMGA2-A } \\
\mathbf{5} \boldsymbol{\mu M}\end{array}$ & $\begin{array}{c}\text { HMGA2-A } \\
\mathbf{5 0} \boldsymbol{\mu} \mathbf{M}\end{array}$ & $\begin{array}{c}\text { HMGA2-B } \\
\mathbf{5} \boldsymbol{\mu M}\end{array}$ & $\begin{array}{c}\text { HMGA2-B } \\
\mathbf{5 0} \boldsymbol{\mu M}\end{array}$ \\
\hline Control & & & & \\
\hline $\begin{array}{c}\text { HMGA2-A } \\
\mathbf{5} \boldsymbol{\mu M}\end{array}$ & $>0.05$ & & & & \\
\hline $\begin{array}{c}\text { HMGA2-A } \\
\mathbf{5 0} \boldsymbol{\mu M}\end{array}$ & $<0.001$ & $<0.001$ & & & \\
\hline $\begin{array}{c}\text { HMGA2-B } \\
\mathbf{5} \boldsymbol{\mu M}\end{array}$ & $<0.01$ & $>0.05$ & $>0.05$ & & \\
\hline $\begin{array}{c}\text { HMGA2-B } \\
\mathbf{5 0} \boldsymbol{\mu M}\end{array}$ & $>0.05$ & $>0.05$ & $<0.01$ & $>0.05$ & \\
\hline
\end{tabular}

using the Tukey-Kramer Multiple Comparisons Test as shown in Table 1.

Compared to the non-HMGA2 control, whose proliferative activity was set as 1 for comparability, a statistically significant increase in proliferation could be detected in chondrocytes treated with either HMGA2-A peptides at both $10 \mu \mathrm{M}(1.94 \mathrm{x}$ increase) and $50 \mu \mathrm{M}$ (1.88x increase), or wild-type HMGA2 protein $(10 \mu \mathrm{M}$, $2.1 \mathrm{x}$ increase). However, no dosage-dependency could be detected for the HMGA2-A peptide, as there was no statistically significant difference of the measured data for both $10 \mu \mathrm{M}$ and $50 \mu \mathrm{M}$. There was also no significant difference in the proliferation inducing activities of wild type HMGA2 and $10 \mu \mathrm{M}$ or $50 \mu \mathrm{M}$ HMGA2-A peptide, respectively, indicating a similar proliferation enhancing effect of the HMGA2-A peptide to the wild type protein.

The measured data for the HMGA2-B peptides, on the other hand, showed no statistically significant differences at both $10 \mu \mathrm{M}(1.54 \mathrm{x}$ increase) and $50 \mu \mathrm{M}$ (0.90x decrease) compared to the non-HMGA2 control, indicating this peptide does not influence the proliferation of chondrocytes as intended. However, there was also no significant difference between HMGA2-B at $10 \mu \mathrm{M}$ and HMGA2-wt, while HMGA2-B at $50 \mu \mathrm{M}$ significantly differed from the wild type protein, even leading to a slight decrease in proliferative activity. This indicates at least some proliferation enhancing effect of the HMGA2-B peptide on the cells that is comparable to wild-type HMGA2, albeit only at the lower concentration, with the effect being diminished or rather reversed at the higher concentration of $50 \mu \mathrm{M}$.

Concerning ADSCs, there was a highly significant increase of proliferation compared to the untreated control at the higher concentration of $50 \mu \mathrm{M}$ HMGA2-A, but not at the lower concentration of $10 \mu \mathrm{M}$. In contrast, only the treatment of ADSCs with $5 \mu \mathrm{M}$ HMGA2-B provided a statistically significant increase of proliferative activity compared to the control, but not the higher concentration of $50 \mu \mathrm{M}$, which even led to a significantly decreased proliferation of cells compared to the HMGA2-A peptide at $50 \mu \mathrm{M}$. 


\section{Discussion}

Recombinant proteins of the human High-MobilityGroup A (HMGA) family including HMGA2 had been shown to significantly increase the proliferative activity of chondrocytes in a dose-dependent manner in an in vitro system utilising cells of porcine origin (Richter et al., 2009). These embryonic proteins are usually absent in fully differentiated adult cells (Rogalla et al., 1996); however, their application to adult chondrocytes led to enhanced growth opening up future possibilities e.g. in hyaline cartilage repair (Richter et al., 2009). To overcome problems caused by e.g. viral delivery of the target gene sequence to cells, which is subject to several factors such as gene dosage, integration into the host genome, and expression of the transgene even after therapy, as well as obstacles of recombinant protein expression in bacterial or eukaryotic expression systems, we developed two synthetic fragments HMGA2-A and HMGA2-B comprising the biologically active parts of HMGA2, the so-called AThooks (Reeves and Nissen, 1990; Geierstanger et al., 1994; Chau et al., 1995; Goodwin, 1998; Reeves, 2000; Cattaruzzi et al., 2007; Cleynen and Van de Ven, 2008). These peptides can be delivered directly to the affected areas and are eliminated over the course of time when not re-applied as needed by therapy, solving the problems mentioned. For assessing their function, the peptides were tested on porcine chondrocytes for their cellular localisation as well as their effects on proliferation in comparison to a non-HMGA2 control and recombinant HMGA2 protein in the same in vitro cell culture system as described before (Richter et al., 2009). In addition, the new peptides were also evaluated on canine adipose tissue derived stem cells, as ADSCs can be differentiated into chondrogenic cells in the presence of lineage-specific induction factors (Zuk et al., 2001; Huang et al., 2004), and are thus another important subject in the field of cartilage repair. Due to HMGA2 proteins being highly conserved between mammals, especially in regard to the functional motifs of the AT-hooks, the sequence of the human HMGA2 were chosen for both peptide and protein. This allows for the use of only one peptide variant across several species as e.g. pig, dog, and human.

Most likely, the detected internalisation of the fluorescently labelled variant of the HMGA2-B peptide (HMGA2-CC) into the nucleus of chondrocytes as well as ADSCs, although the fragment lacks the carboxyterminal acidic part of the wild type protein, is due to the nuclear localisation signal on the second AT-hook of the HMGA2 peptide. From this it can be assumed that either the complete peptide or at least a fragment thereof comprising the labelled N-terminus up to the second AT-hook (this would correspond somehow to the shorter HMGA2-A peptide which lacks the $20 \mathrm{C}$-terminal amino acids of HMGA2-B including AT-hook 3) are located into the nucleus, as the presence of the first AT-hook alone is not sufficient for nuclear transport, while the presence of the second AT-hook is necessary (Cattaruzzi et al., 2007). The fluorescence found in the cytoplasm would then be caused by either or both intact peptides not yet transported into the nucleus as well as peptide fragments lacking the nuclear transport signal of the second AT-hook.

However, concerning cell proliferation, the administration of recombinant HMGA2 to porcine chondrocytes could reproduce the same positive effect on proliferation as described before (Richter et al., 2009), as there was highly significant difference in proliferation to the untreated control. The synthetic HMGA2-A peptide led to a comparable effect on proliferation to the wild type protein as there was no statistically significant difference in cell proliferation at both $10 \mu \mathrm{M}$ and $50 \mu \mathrm{M}$ HMGA2-A compared to HMGA2-wt, leading to the conclusion that it is an adequate alternative to the recombinantly produced protein. On the other hand, HMGA2-B did not show any significant difference to the untreated control group at both $10 \mu \mathrm{M}$ and $50 \mu \mathrm{M}$, and only had comparable effect to the wild type protein at $10 \mu \mathrm{M}$, while there was a statistically significant lower proliferation at $50 \mu \mathrm{M}$, showing that this larger peptide might probably be detrimental to chondrocyte proliferation at higher levels. The fact that no increase (HMGA2-A) or rather a decrease (HMGA2-B), respectively, occurs at $50 \mu \mathrm{M}$ compared to $10 \mu \mathrm{M}$, might also indicate that there is saturation of cells or their DNA, respectively, at higher concentrations of the peptides, which in case of HMGA2-B might also inhibit cellular processes required for proliferation. As the peptides bind to the minor groove of AT-rich DNA, there are probably only a limited number of binding sites available for the peptide molecules which might be occupied from a certain concentration, leading to either no or detrimental effects on the cells.

Concerning ADSCs, a beneficial effect on the proliferation of these cells could be detected as well, at least at the higher concentration of $50 \mu \mathrm{M}$ HMGA2-A. On the other hand, the larger HMGA2-B peptide caused a significant increase of proliferative activity only at the lower concentration of $5 \mu \mathrm{M}$, while the higher dose of $50 \mu \mathrm{M}$ led to a reduced proliferation compared to $5 \mu \mathrm{M}$ HMGA2-B, which is similar to the results obtained from chondrocytes, albeit at a lower degree. Differences in response to HMGA2 peptides between chondrocytes and ADSCs - besides comparing distinct cell types - might probably be due to possible different chromatin stages of these cell types. For example, anti-proliferative activities of HMGA2 have been described depending on the cellular context (Narita et al., 2006).

However, the proliferative effects evoked by the HMGA2-A peptide open up further possibilities in e.g. tissue engineering, comparable to those of HMGA2-wt. Due to the presence of two AT-hooks and the nuclear localisation signal, this peptide comprises similar functions to the recombinant protein, but instead can be synthesised up to industrial scale without the need of recombinant expression systems. Thus, this peptide as a proliferation inducing/enhancing agent is of great importance for future applications in e.g. cartilage repair and further tissue engineering applications, as well as in further fields such as e.g., stem cell research. 


\section{Acknowledgement}

This work was supported in part by the German Excellence Cluster REBIRTH (From Regenerative Biology to Reconstructive Therapy, Hanover) within the Excellence Initiative of the German Federal Ministry of Education and Research and the German Research Foundation.

\section{References}

Battista S, Fidanza V, Fedele M, Klein-Szanto AJ, Outwater E, Brunner H, Santoro M, Croce CM, Fusco A (1999) The expression of a truncated HMGI-C gene induces gigantism associated with lipomatosis. Cancer Res 59: 4793-4797.

Cattaruzzi G, Altamura S, Tessari MA, Rustighi A, Giancotti V, Pucillo C, Manfioletti G (2007) The second at-hook of the achitectural transcription factor HMGA2 is determinant for nuclear localization and function. Nucleic Acids Res 35: 1751-1760.

Chau KY, Patel UA, Lee KL, Lam HY, Crane-Robinson C (1995) The gene for the human architectural transcription factor HMGI-C consists of five exons each coding for a distinct functional element. Nucleic Acids Res 23: $4262-$ 4266.

Cleynen I, Van de Ven WJ (2008) The HMGA proteins: A myriad of functions (Review). Int J Oncol 32: 289-305.

Dominici M, Le Blanc K, Mueller I, Slaper-Cortenbach I, Marini F, Krause D, Deans R, Keating A, Prockop D, Horwitz E (2006) Minimal criteria for defining multipotent mesenchymal stromal cells. The International Society for Cellular Therapy Position Statement. Cytotherapy 8: 315317.

Fedele M, Berlingieri MT, Scala S, Chiariotti L, Viglietto G, Rippel V, Bullerdiek J, Santoro M, Fusco A (1998) Truncated and chimeric HMGI-C genes induce neoplastic transformation of NIH3T3 murine fibroblasts. Oncogene 17: 413-418.

Geierstanger BH, Volkman BF, Kremer W, Wemmer DE (1994) Short peptide fragments derived from HMGI/Y proteins bind specifically to the minor groove of DNA. Biochemistry 33: 5347-5355.

Goodwin G (1998) The high mobility group protein, HMGI-C. Int J Biochem Cell Biol 30: 761-766.

Huang JI, Zuk PA, Jones NF, Zhu M, Lorenz HP, Hedrick MH, Benhaim P (2004) Chondrogenic potential of multipotential cells from human adipose tissue. Plast Reconstr Surg 113: 585-594.

Narita M, Krizhanovsky V, Nunez S, Chicas A, Hearn SA, Myers MP, Lowe SW (2006) A novel role for highmobility group a proteins in cellular senescence and heterochromatin formation. Cell 126: 503-514.

Noro B, Licheri B, Sgarra R, Rustighi A, Tessari MA, Chau KY, Ono SJ, Giancotti V, Manfioletti G (2003) Molecular dissection of the architectural transcription factor HMGA2. Biochemistry 42: 4569-4577.

Reeves R (2000) Structure and function of the HMGI(Y) family of architecturaltranscription factors. Environ Health Perspect 108 Suppl 5: 803-809.

Reeves R, Beckerbauer L (2001) HMGI/Y proteins: Flexible regulators of transcription and chromatin structure. Biochim Biophys Acta 1519: 13-29.

Reeves R, Beckerbauer LM (2003) Hmga Proteins as Therapeutic Drug Targets. Prog Cell Cycle Res 5: 279-286.

Reeves R, Nissen MS (1990) The A.T-DNA-binding domain of mammalian high mobility group I chromosomal proteins. A novel peptide motif for recognizing DNA structure. J Biol Chem 265: 8573-8582.

Richter A, Hauschild G, Murua Escobar H, Nolte I, Bullerdiek J (2009) Application of high-mobility-group-A proteins increases the proliferative activity of chondrocytes in vitro. Tissue Eng Part A 15: 473-477.

Rogalla P, Drechsler K, Frey G, Hennig Y, Helmke B, Bonk U, Bullerdiek J (1996) HMGI-C Expression patterns in human tissues. Implications for the genesis of frequent mesenchymal tumors. Am J Pathol 149: 775-779.

Schwanbeck R (1995) Die Phosphorylierung der architektonischen HMGI(Y)-Chromatinproteine: Modulation der Struktur und DNA-Bindung. Cuvillier Verlag, Goettingen.

Yie J, Liang S, Merika M, Thanos D (1997) Intra- and intermolecular cooperative binding of high-mobility-group protein $\mathrm{I}(\mathrm{Y})$ to the beta-interferon promoter. Mol Cell Biol 17: 3649-3662.

Zuk PA, Zhu M, Mizuno H, Huang J, Futrell JW, Katz AJ, Benhaim P, Lorenz HP, Hedrick MH (2001) Multilineage cells from human adipose tissue: Implications for cell-based therapies. Tissue Eng 7: 211-228.

Editor's Note: Since all questions/comments by the reviewers were answered by text changes, there is no "Discussion with Reviewers" section. 